\title{
Long term results of PDR brachytherapy for lip cancer
}

\author{
Bengt Johansson, MD, PhD', Leif Karlsson, MSc', Lennart Hardell, MD, PhD², Jan Persliden, MSc, PhD² \\ 'Department of Oncology, ${ }^{2}$ Department of Medical Physics, Örebro University Hospital and Örebro University. Sweden
}

\begin{abstract}
Purpose: To evaluate the long time outcome with regard to local tumour control and side effects of a pulsed dose rate (PDR) monobrachytherapy of primary or recurrent cancer of the lip.

Material and methods: Between 1995 and 2007 we treated 43 patients with primary or recurrent clinical T1-T3N0 lip cancers. There were $22 \mathrm{~T} 1$ patients (51\%), $16 \mathrm{~T} 2$ (37\%) and 5 T3 cases (12\%). A median dose of 60 (55-66) Gy was given, depending on the tumour volume. The PDR treatment was delivered with $0.83 \mathrm{~Gy} /$ pulse every second hour for 5.5-6.5 days. The patients were followed for a median of 55 (1-158) months.

Results: The 2-, 5- and 10-year rates of actuarial local control were $97.6 \%, 94.5 \%$ and $94.5 \%$, overall survival $88.0 \%, 58.9 \%$ and $39.1 \%$, disease free survival $92.7 \%, 86.4 \%$ and $86.4 \%$ respectively. The regional control rate was $93 \%$. One patient $(2 \%)$ developed distant metastases. A dosimetrical analysis showed a mean treated volume of 14.9 (3.0-56.2) $\mathrm{cm}^{3}$. Long-term side effects were mild and the cosmetic outcome excellent, except for 1 case ( $\left.2 \%\right)$ of soft tissue necrosis and 1 case $(2 \%)$ of osteoradionecrosis.

Conclusions: Local outcome is excellent and similar to other published studies of continuous low dose rate (cLDR) brachytherapy.

Key words: brachytherapy, PDR, lip cancer.

\section{Purpose}

The incidence of lip cancer for men has decreased over the last 10 years but the trend for woman is the opposite, probably due to changes in smoking behaviour. In total there were 152 new incident cases in the Swedish cancer registry in 2007 [1]. There are no randomised studies comparing different treatment strategies. Surgery is probably the most frequently used therapy for lip cancer. Long-term local cure rate is similar for surgery and radiotherapy [2]. Two large ESTRO surveys $1983(n=1896)$ and $1993(n=2794)$ have clearly demonstrated the effectiveness of low dose rate (LDR) interstitial brachytherapy (BT) in T1-T4 lip cancer with $5-10 \%$ local failure rate at 5 years follow-up [3]. Up to now experience with brachytherapy has been reported mainly for LDR manual Ir-wire/needle afterloading which has now more or less been discarded for reasons of radiation protection. Machine afterloading by high dose rate (HDR) and pulsed dose rate (PDR) brachytherapy are the modern options instead. Only a few papers report the long time outcome with modern PDR $[4,5]$ or HDR brachytherapy [6]. PDR brachytherapy was introduced around 1990 as a substitute for LDR. Small pulses of HDR are given hourly or every second hour so that the overall dose rate and total dose will be equal to the LDR schedule [7]. We have not found any systematic studies with long time results published on lip cancer and PDR fractionation.
The aim of this study was to investigate the long-term outcome with respect to local tumour control and complications in patients with PDR monobrachytherapy. Our hypothesis is that PDR brachytherapy proves to be as effective as LDR brachytherapy documented in reports based on earlier experience. The regional ethical committee approved this study.

\section{Material and methods \\ Study cohort}

From the registry of the Head and Neck Oncology Centre of Örebro University Hospital we identified 67 patients with primary or recurrent lip cancer treated between September 1995 and October 2007. The treatment for $43(64 \%)$ of them was PDR monobrachytherapy. The median age was 74 (37-92) years. The treatment was decided in our institutional multidisciplinary consensus weekly meeting. To be included in the study patients had to have either a macroscopic tumour or microscopic remnants after non-radical surgery and also a proven histology of primary or recurrent lip cancer T1-T3N0M0. Patient characteristics are shown in Table 1.

\section{Implant technique}

The implant was performed under local anaesthesia with horizontally placed plastic catheters in a parallel, rhomboid, 
Table 1. Clinical data for 43 patients treated for lip cancer

\begin{tabular}{|c|c|c|}
\hline Patient characteristics & $n$ & $\%$ \\
\hline \multicolumn{3}{|l|}{ Age median 74 (37-92) years: } \\
\hline male & 26 & 60 \\
\hline female & 17 & 40 \\
\hline \multicolumn{3}{|l|}{ TN-stage: } \\
\hline T1NO & 22 & 51 \\
\hline T2NO & 16 & 37 \\
\hline T3NO & 5 & 12 \\
\hline \multicolumn{3}{|l|}{ Histology: } \\
\hline squamous cell carcinoma & 38 & 89 \\
\hline adenoidcystic carcinoma & 4 & 9 \\
\hline basal cell carcinoma & 1 & 2 \\
\hline \multicolumn{3}{|l|}{ Grade (squamous cell carcinoma): } \\
\hline low & 23 & 60 \\
\hline medium & 12 & 32 \\
\hline high & 3 & 8 \\
\hline \multicolumn{3}{|l|}{ Treatment set-up: } \\
\hline primary macroscopical appearant & 23 & 53 \\
\hline primary microscopical appearant & 11 & 26 \\
\hline recurrent macroscopical appearant & 7 & 16 \\
\hline recurrent microscopical appearant & 2 & 5 \\
\hline \multicolumn{3}{|l|}{ Localisation: } \\
\hline lower lip & 34 & 79 \\
\hline upper lip & 7 & 16 \\
\hline lip commisure & 2 & 5 \\
\hline
\end{tabular}

quadratic or triangular distribution according to the Paris rules (Fig. 1). The median number of catheters was 4 [3-7]. If the tumour was exophytic we always put 1-2 catheters with one part in the air outside the tumour surface by means of an outer distance tubing. Due to the anatomy of the lip, the distances between the catheters were short. Some patients with tumours of the upper lip or commisure were per- formed under general anaesthesia. All patients received antibiotics during the implant, the treatment period and the following 7 days.

\section{Dosimetry}

Two orthogonal films of the implant were taken. A 3D volume of the implant geometry was reconstructed from these two orthogonal films. The mean central dose (MCD) was the arithmetic mean of the local minimum doses in the dose points between the applicators in the central plane according to the Paris system. The prescribed dose was the minimum target dose (MTD) and was defined as $85 \%$ of MCD. The dose distribution was optimized using standard geometrical optimization on volume. The dose calculations were made in the Nucletron planning system (NPS, v.10 Nucletron International BV, Veenendaal, the Netherlands). Since March 2006 we have gradually introduced 3D CT-based planning (Plato, v.14 Nucletron International BV, Veenendaal, the Netherlands).

The treatment was given by pulsed irradiation and delivered with an HDR Ir-192 source, delivered with a microSelectron PDR (Nucletron International BV, Veenendaal, the Netherlands). The minimum target dose was $60 \mathrm{~Gy}$ given $(n=34)$ in 12 pulses per day (interval 2 hours) over 6 days where the dose per pulse was $0.83 \mathrm{~Gy}$. A dose of $55 \mathrm{~Gy}$ was preferred for residual microscopical disease after non-radical surgery $(n=6)$ and the higher dose levels (> 60 Gy) to macroscopic T2-T3, large volume tumours $(n=3)$. The treatment was started within a median of 34 (9-145) days after diagnosis. The biologically effective dose (BED) and equivalent dose $2 \mathrm{~Gy} /$ fraction $\left(\mathrm{EQD}_{2}\right)$ for $60 \mathrm{~Gy}$ PDR $\left(\mathrm{T}_{1 / 2}=\right.$ $=1 \mathrm{~h}$ for repair of sublethal damage) fractionation is 68.2 and $56.8 \mathrm{~Gy}$, respectively, for tumour $(\alpha / \beta=10)$ and 87.2 and $52.3 \mathrm{~Gy}$, respectively, for late effects $(\alpha / \beta=3)$ [8]. Similar, calculations for $60 \mathrm{~Gy}$ continuous low dose rate brachytherapy (cLDR) give 68.6 and 57.2 Gy for tumours and 88.5 Gy and 53.1 Gy, respectively for late effects. All treatments were reviewed and evaluated as recommended in ICRU 58 [9]. The mean treated volume was $14.9(3.0-56.2) \mathrm{cm}^{3}$. Dosimetric and volumetric data are shown in Table 2.

\section{Follow up}

All patients were seen after 2-4 weeks to monitor acute reaction and early complications.
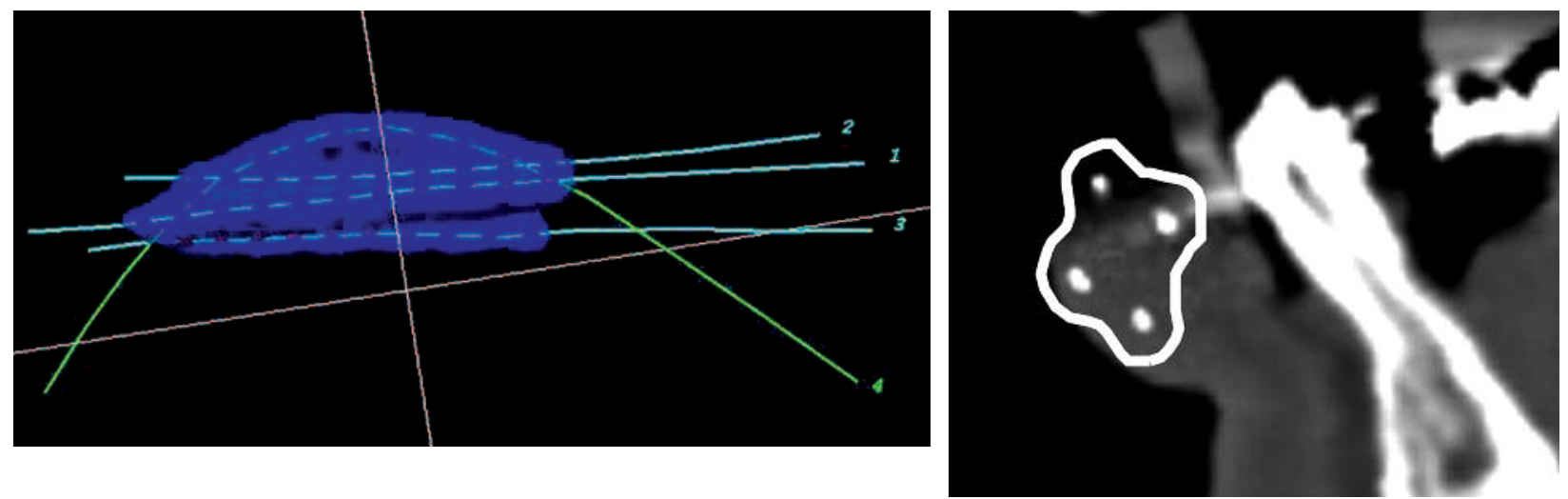

Fig. 1. Coronar and sagital view of the most common implant technique in the present serie 
Table 2. Dosimetric and volumetric data for treated lip cancers

\begin{tabular}{lcc} 
Variable & Mean & Range \\
\hline Treated volume $\left(\mathrm{cm}^{3}\right)$ & 14.9 & $3.0-56.2$ \\
\hline 150\% isodose volume $\left(\mathrm{cm}^{3}\right)$ & 4.4 & $0.9-13.6$ \\
\hline 200\% isodose volume $\left(\mathrm{cm}^{3}\right)$ & 1.8 & $0.4-5.7$ \\
\hline DNR (= V150\%/V100\%) $[17]$ & 0.3 & $0.2-0.5$ \\
\hline UI [18] & 1.5 & $1.2-1.8$ \\
\hline QI [19] & 1.6 & $1.2-2.0$ \\
\hline Instantaneoues dose rate $(G y / h)$ & 12.8 & $3.2-35.6$ \\
\hline Pulse average dose rate $(G y / h)$ & 0.417 & \\
\hline RAKR, reference air kerma rate $\left(\mathrm{mGym}{ }^{2} / \mathrm{h}\right)$ & 1.8 & $0.7-4.3$ \\
\hline TRAK, total reference air kerma $(\mathrm{mGy})$ & 0.15 & $0.05-0.35$
\end{tabular}

The patient was then followed by clinical examination every 3-4 months for the first two years, every 6 months for years 3 and 4 and by annual visits thereafter. At least 5 years follow up was our intention. After this we were able to keep in contact with the patient through telephone interviews. The patient was examined with biopsy or appropriate radiological imaging if there was any suspicion of abnormality.

\section{Statistical methods}

Data from a clinical database was retrieved and analysed. Local tumour control, disease free survival and overall survival were estimated with the Kaplan-Meier analysis. All data was analysed with the Stata SE 10.1 software (Stata/SE 10.1 for Windows, StataCorp, College Station, TX).

\section{Results}

\section{Treatment outcome}

The median clinical follow up time was 33 (1-128) months and contact follow up 54 (1-158) months. No patient was lost for follow up. In total we found $2(5 \%)$ local failures. One patient with low grade, T1N0, recurred locally after 4 months. He is still alive after two other local relapses and salvage surgeries. The second local failure, after 28 months, was an intermediate grade, T2N0, lip cancer in a patient treated with surgery and external beam radiotherapy (60 Gy) for a tongue cancer many years before. He was successfully salvaged by surgery and is still alive and well. Three patients $(7 \%)$ had regional failures; one T2N0 in the commisure at 9 months was treated by neck dissection and postoperative radiotherapy but developed two new lymph node recurrences and died 6 months later. The second regional recurrence, at 15 months, occurred in a patient with a T1N0 adenoidcystic cancer. She was treated by 68 Gy external beam radiotherapy. This patient was the only one in this series who developed distant metastases in form of pleural carcinosis and died 6 months later. The third patient treated after non-radical surgery for a T1N0 cancer of the upper lip developed a tumour in the

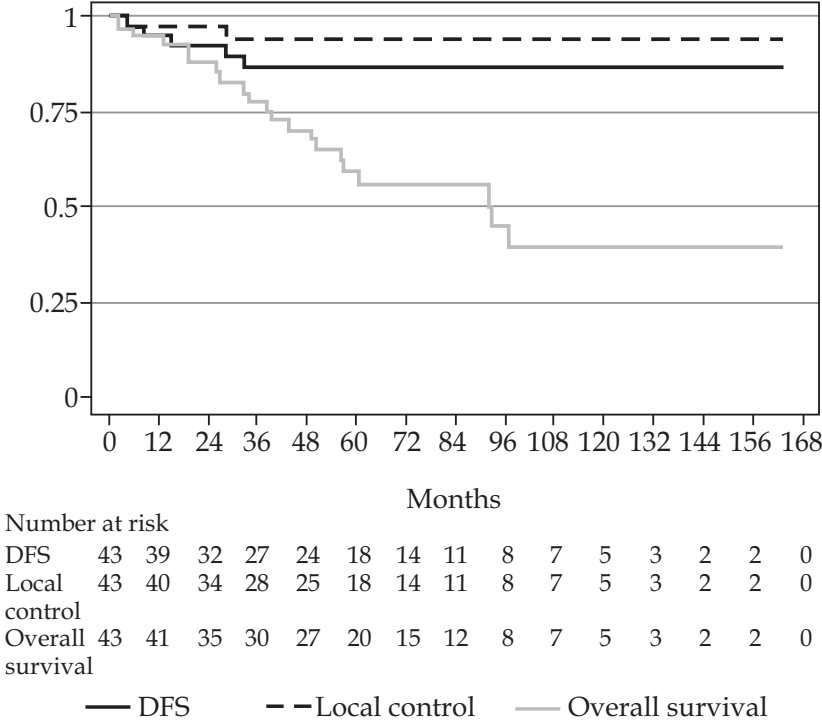

Fig. 2. Kaplan-Meier plot of local control, disease free survival (DFS) and overall survival

ipsilateral maxilla and subcutaneous tissue at 32 months and had a non-radical surgery. She is still alive 2 years later with no progression and local control in the lip. Actuarial local control at 2, 5 and 10 years was, 97.6\%, 94.5\% and 94.5\%, respectively. Actuarial disease free survival (DFS) rates at 2,5 and 10 years were $92.7 \%, 86.4 \%$ and $86.4 \%$, respectively. Actuarial overall survival rates (OS) at 2, 5 and 10 years were $88.0 \%, 58.9 \%$ and $39.1 \%$, respectively (Fig. 2 ).

\section{Side effects}

All patients had an intensive mucositis in the treatment volume starting at 1 week after treatment and fading out 4 weeks later on. We noticed one patient $(2 \%)$ with a transient soft tissue necrosis. Another patient treated by $60 \mathrm{~Gy}$ postoperative radiotherapy for a tongue cancer (as mentioned above), developed an osteonecrosis concomitant to the local failure, possibly induced by radiation. There were 6 patients (14\%) who noticed some saliva leakage due to some stiffness or irregularities in the lip surface. Three patients $(7 \%)$ had increased parodontitis in the neighbourhood of the treatment area. To protect the dental gingiva we asked the patient to put a small soft plastic plate of $3 \mathrm{~mm}$ thickness between the teeth and the lip during the pulses at daytime. To protect the other lip we asked the patient to keep the mouth slightly open during pulses when the patient was awake. The cosmetic outcome was in general very good. In some patients there was slight asymptomatic fibrosis and sclerosis (Grade 1 according to SOMA/LENT skin toxicities) but with no telangiectasias [10].

\section{Discussion}

In general, surgical excision is the simplest treatment for limited lip cancer. A $10 \mathrm{~mm}$ safety resection margin is often recommended around the tumour. If Mohs' surgery is performed or if the excision is checked by frozen-section 
Table 3. Five years local control rate (\%) of lip cancer in published series

\begin{tabular}{|c|c|c|c|c|c|c|c|}
\hline Studie & BT & $n$ & $\mathrm{FU}(\mathrm{m})$ & $\mathrm{T} 1$ & $\mathrm{~T} 2$ & T3 & All \\
\hline GEC-ESTRO 1983 [3] & LDR & 1267 & 60 & 98.4 & 96.6 & 90 & 96.6 \\
\hline GEC-ESTRO 1993 [3] & LDR & 2794 & 60 & 95 & 91.8 & 81 & 94 \\
\hline Present study & PDR & 43 & 54 & 95 & 94 & 100 & 95 \\
\hline Valencia $[6]^{\star}$ & HDR & 39 & 18 & 100 & 83 & 75 (T4) & 87 \\
\hline
\end{tabular}

*At median follow-up. 12 patients classified as T4 due to skin extension. No T3 cases in this study

analysis the margin can be reduced [11]. In a review longterm local failure rate by non-Mohs'surgery was $10.5 \%$ and $2.3 \%$ with the Mohs' technique [12]. At our hospital we consider brachytherapy for tumours larger than $10 \mathrm{~mm}$ and for all tumours in the commisure area and upper lip. A dose of 60-70 Gy with continuous LDR is considered optimal for T1 and T2 tumours [3]. Our PDR dose is chosen to be similar to 60 Gy with cLDR, which is in the lower range recommended from GEC-ESTRO [13].

In our series, $31 \%$ of the patients were treated after nonradical surgery. Radiation treatment in these cases is important in order to prevent local failure [14]. One issue with PDR brachytherapy is that the patient must have a stable and non-kinking flexible tube implant for 6 days. We usually arrange the catheters horizontal in rhomboid configuration with one big transfixed loop on the surface, lying in an outer distance tubing (see Fig. 1). We have had very few technical problems with this implant technique and the patient tolerance is very good.

In T3 tumours the risk of lymph node spread becomes more important and brachytherapy only may result in some lymph node failures in these cases [3]. Tumours with growth to the labial mucosa have a higher risk of lymphatic spread [15]. Despite this, two of our regional failures were T1-T2 tumours (one of the upper lip and one in the commisure area). The third regional failure in the maxilla area might have developed from a perineural infra orbital spread, which is described in literature [16].

Results on the long-term outcome on lip cancer with modern machine afterloading (PDR and HDR) are hard to find. In a publication from Gdansk on PDR brachytherapy they treated 23 patients $(6 \mathrm{~T} 1,15 \mathrm{~T} 2,1 \mathrm{~T} 3$ and $1 \mathrm{~T} 4)$ with only brachytherapy (60-70 Gy). The local control rate was not exactly stated for lip cancers but was $93.7 \%$ for the brachytherapy only group (mainly lip cancers) at 22 months [4]. The Erlangen publication on PDR brachytherapy included 7 patients with lip cancer (4 with T1 and 3 with T2 tumours): they had a five-year local control rate of $100 \%$. The results of HDR brachytherapy on lip cancer with a short median follow up of 18 (1-36) months is published from Valencia (Table 3). The shortcomings of this study is the limited number of patients and the retrospective approach. On the other hand no patients is lost for follow-up and the follow up time is long. Our local control rate per T-stage and overall compares well with the GEC-ESTRO surveys (Table 3). The cosmetic outcome in our study was excellent in general. Usually there is a small deformation at the biopsy site and some depigmentation and local fibrosis. One patient treated after non-radical surgery for a T1N0 cancer of the upper lip developed a tumour in the ipsilateral maxilla and subcutaneous tissue at 32 months and had a non-radical surgery. We considered this to be a regional recurrence through lymph vessel spread but it is uncertain if there is a connection to the original cancer of the upper lip or maybe a new primary.

\section{Conclusions}

This study on the long-term outcome of sole PDR brachytherapy of T1-T3 lip cancer shows excellent local control rate with very limited side effects. The study strongly supports that PDR fractionation is as effective as LDR brachytherapy.

\section{Acknowledgment}

The Weiderman donation, Svenssons memorial foundation and research committee of Örebro county council supported this work. The authors would like to thank Michael Carlberg MSc for statistical calculation and Terence Kearey for English proof reading.

\section{References}

1. The National Board of Health and Welfare (Socialstyrelsen). Cancer incidence in Sweden 2007. Stockholm, 2008 [cited 2009 2009-08-26]; available from: http:/ / www.socialstyrelsen.se/NR/ rdonlyres / 64AD2A81-FF9F-459F-B0CF-CA955B7E8513/ 13410/200812516_rev2.pdf.

2. de Visscher JG, Botke G, Schakenraad JA et al. A comparison of results after radiotherapy and surgery for stage I squamous cell carcinoma of the lower lip. Head Neck 1999; 21: 526-530.

3. Gerbaulet A, Pötter R, Mazeron J-J et al. [eds]. The GEC ESTRO Handbook of Brachytherapy. ESTRO, Brussels 2002.

4. Ziemlewski A, Zienkiewicz J, Serkies K et al. Preliminary report of pulsed dose rate brachytherapy in head-and-neck cancer. Strahlenther Onkol 2007; 183: 512-516.

5. Strnad V, Melzner W, Geiger M et al. Role of interstitial PDR brachytherapy in the treatment of oral and oropharyngeal cancer. A single-institute experience of 236 patients. Strahlenther Onkol 2005; 181: 762-767.

6. Guinot JL, Arribas L, Chust ML et al. Lip cancer treatment with high dose rate brachytherapy. Radiother Oncol 2003; 69: 113-115.

7. Brenner DJ, Hall EJ. Conditions for the equivalence of continuous to pulsed low dose rate brachytherapy. Int J Radiat Oncol Biol Phys 1991; 20: 181-190.

8. Dale RG, Huczkowski J, Trott KR. Possible dose rate dependence of recovery kinetics as deduced from a preliminary analysis of the effects of fractionated irradiations at varying dose rates. Br J Radiol 1988; 61: 153-157.

9. ICRU. Dose and Volume Specification for Reporting Interstitial Therapy. International Comission on Radiation Units and Measurements. Bethesda, 1997.

10. LENT SOMA tables. Radiother Oncol 1995; 35: 17-60. 
11. de Visscher JG, van den Elsaker K, Grond AJ et al. Surgical treatment of squamous cell carcinoma of the lower lip: evaluation of long-term results and prognostic factors - a retrospective analysis of 184 patients. J Oral Maxillofac Surg 1998; 56: 814-820; discussion: 820-811.

12. Rowe DE, Carroll RJ, Day CL Jr. Prognostic factors for local recurrence, metastasis, and survival rates in squamous cell carcinoma of the skin, ear, and lip. Implications for treatment modality selection. J Am Acad Dermatol 1992; 26: 976-990.

13. Mazeron JJ, Ardiet JM, Haie-Meder C et al. GEC-ESTRO recommendations for brachytherapy for head and neck squamous cell carcinomas. Radiother Oncol 2009; 91: 150-156.

14. Babington S, Veness MJ, Cakir B et al. Squamous cell carcinoma of the lip: is there a role for adjuvant radiotherapy in improving local control following incomplete or inadequate excision? ANZ J Surg 2003; 73: 621-625.

15. Bentley JM, Barankin B, Lauzon GJ. Paying more than lip service to lip lesions. Can Fam Physician 2003; 49: 1111-1116.

16. Bhatnagar AK, Heron DE, Schaitkin B. Perineural invasion of squamous cell carcinoma of the lip with occult involvement of the infra-orbital nerve detected by PET-CT and treated with MRI-based IMRT: a case report. Technol Cancer Res Treat 2005; 4: 251-253.

17. Saw CB, Suntharalingam N. Quantitative assessment of interstitial implants. Int J Radiat Oncol Biol Phys 1991; 20: 135-139.

18. Anderson LL. A "natural" volume-dose histogram for brachytherapy. Med Phys 1986; 13: 898-903.

19. Thomadsen BR HP, van der Larse R, Edmundson G et al. Treatment planning and optimisation. In: Nag S [ed.]. High dose rate brachytherapy. A textbook. Futura, New York 1994; 79-145. 